\title{
Separation of some hydroxycarboxylic acids by capillary isotachophoresis in the presence of neutral cyclodextrins
}

\author{
J. Sádecká ${ }^{1}$, A. Hercegová ${ }^{1}$, J. Polonsky ${ }^{1}$ ữ and Z. Chilmonczyk ${ }^{2}$ \\ ${ }^{1}$ Department of Analytical Chemistry, Faculty of Chemical Technology, Radlinského 9, \\ 81237 Bratislava, Slovak Republic \\ ${ }^{2}$ Pharmaceutical Research Institute, ul. Rydygiera 8, 01-793 Warsaw, Poland
}

\begin{abstract}
The aim of this work was to study the various electrolyte systems in which hydroxycarboxylic acids can be separated by capillary isotachophoresis. Using $\beta$-cyclodextrin as additive to the leading electrolyte, the complete separation of hydroxycarboxylic acids was achieved. The results confirmed the significant influence of the cyclodextrin concentration and $\mathrm{pH}$ on the resolution of hydroxycarboxylic acids.
\end{abstract}

Key words. Isotachophoresis - hydroxycarboxylic acids - cyclodextrins - inclusion complexes.

\section{Introduction}

Complex formation in isotachophoresis is an important tool for improvement in the separation of sample ions. This possibility is mainly used for inorganic ions where the effective mobilities are less sensitive to $\mathrm{pH}$ changes. The possibility of influencing the effective mobilities of organic ions through complex formation may be useful in the separation of structurally related compounds with similar acid-base behaviour where the resolution cannot be achieved by varying the $\mathrm{pH}$. The use of cyclodextrin as a neutral macrocyclic complex-forming agent seems to be advantageous for the resolution of similar organic compounds [1-6].

The analysis of carboxylic acids, such as mono-, poly, and hydroxy-carboxylic acids, is extremely important and nearly all separation techniques have been applied to them. Good results have been obtained by various research workers who analysed these substances by liquid chromatography [7-14], electrophoresis [15-18] and isotachophoresis [19-26]. Many references can easily be found and they are not cited here because only incomplete list could be given. So far, little attention has been paid to the separation of hydroxycarboxylic acids by isotachophoresis.

In this work, we discuss various electrolyte systems in which hydroxycarboxylic acids can be analysed by isotachophoresis. Several operational systems are considered below in order to show complex formation and the variations in the effective mobilities.

\section{Experimental}

\section{Chemicals}

Deionized and redistilled water was used in the preparation of the solutions of the electrolytes and compounds investigated. All chemicals were of the highest quality commercially available. The solutes investigated (Tab. I) were provided by Pharmaceutical Research Institute, Warsaw, Poland.

Sample solutions $(2 \mathrm{mmol} / \mathrm{L})$ were prepared by dissolving each substance in water and were stored in a refrigerator. $\beta$-cyclodextrin $(\beta C D)$ was obtained from Merck (Darmstadt). Heptakis (2,3,6-tri-O-methyl)- $\beta$-cyclodextrin $(\mathrm{TM} \beta \mathrm{CD})$ was synthesised by the method of Nowotny et al. [27].

\section{Apparatus}

Isotachophoretic experiments were performed using a Villa Labeco ZKI 02 column-coupling isotachophoretic analyser (Slovak Republic) equipped with capillaries made of a fluorinated ethylene-propylene copolymer.

\section{Operating conditions}

The operating conditions are given in table II. In the case of one-dimensional isotachophoresis, the preseparation and the analytical capillary was filled with leading 


\section{Original articles}

Table I. Hydroxycarboxylic acids investigated.

\begin{tabular}{|c|c|c|c|}
\hline No. & Compound & $\begin{array}{l}p K_{1}{ }^{(a)} \\
p K_{2}{ }^{(a)}\end{array}$ & $\begin{array}{c}\mu_{o}(a) \\
\left(\mathrm{cm}^{2} V^{-1} s^{-1} \cdot 10^{5}\right)\end{array}$ \\
\hline \multicolumn{4}{|c|}{ Group A } \\
\hline 1 & tartaric acid & $\begin{array}{l}3.036 \\
4.366\end{array}$ & $\begin{array}{l}32.6 \\
60.7\end{array}$ \\
\hline 2 & malic acid & $\begin{array}{l}3.460 \\
5.050\end{array}$ & $\begin{array}{l}32.6 \\
59.0\end{array}$ \\
\hline $\begin{array}{l}3 \\
4\end{array}$ & $\begin{array}{l}\text { glyceric acid } \\
\text { 2-methylmalic acid }\end{array}$ & 3.737 & 36.4 \\
\hline 5 & lactic acid & 3.860 & 36.5 \\
\hline 6 & 2-hydroxybutyric acid & 3.979 & 34.3 \\
\hline 7 & 2-hydroxy-3-methylbutyric acid & & \\
\hline 8 & 2-hydroxy-2-methylbutyric acid & & \\
\hline 9 & 2-hydroxy-4-methylvaleric acid & & \\
\hline \multicolumn{4}{|c|}{ Group B } \\
\hline 10 & mandelic acid & 3.411 & 28.3 \\
\hline 11 & atrolactic acid & & \\
\hline 12 & p-hydroxymandelic acid & & \\
\hline 13 & 3-phenyllactic acid & & \\
\hline 14 & 3-(4-hydroxyphenyl)lactic acid & $4.76^{\text {(b) }}$ & \\
\hline 15 & 2-hydroxy-4-phenylbutyric acid & & \\
\hline 16 & hexahydromandelic acid & & \\
\hline 17 & tropic acid & & \\
\hline
\end{tabular}

$\mu_{\mathrm{o}}$ absolute mobility; (a) Ref. [28]; (b) Ref. [29].

electrolytes LE1 - LE6. In the case of two-dimensional isotachophoresis, the preseparation capillary was filled with LE2. The analytical capillary was run with CD-modified leading electrolyte (either LE1 or LE2).

\section{Calibration}

Calibration analysis were carried out in the analytical capillary where six calibration points were measured within the range $0.08-4.0 \mathrm{mmol} / \mathrm{L}$ (injection $1 \mu \mathrm{L}$ ). The upper calibration limits were those concentrations where mixed isotachophoretic zones occurred.

\section{Results and discussion}

The ITP resolution was determined on the bases of the step height differences of the compounds. In all system the chloride ion (leading ion) has a step height of 0 . The step heights of the analytes are given in $\mathrm{mV}$ from the level of the leading electrolyte zone. These values are given for comparison of the various electrolyte systems. According to the accuracy and reproducibility of the measurements, a value of $1 \%$ of caproic acid step height (terminating ion) was specified as the lowest step height difference limit in order to achieve
Table II. Electrolyte systems and conditions for isotachophoresis.

\begin{tabular}{|c|c|}
\hline Parameter & Conditions \\
\hline \multicolumn{2}{|c|}{ Leading electrolytes $(\mathrm{LE})^{(1)}$} \\
\hline LE1 & $\begin{array}{l}10 \mathrm{mmol} / \mathrm{L} \mathrm{HCl} \text { adjusted with } \beta \text {-alanine to } \mathrm{pH} 3.0 \\
\mathrm{LE} 1+5 \mathrm{mmol} / \mathrm{L} \beta \mathrm{CD} \\
\mathrm{LE} 1+10 \mathrm{mmol} / \mathrm{L} \beta \mathrm{CD} \\
\mathrm{LE} 1+5 \mathrm{mmol} / \mathrm{L} \mathrm{TM} \beta \mathrm{CD} \\
\mathrm{LE} 1+10 \mathrm{mmol} / \mathrm{L} \mathrm{TM} \beta \mathrm{CD}\end{array}$ \\
\hline LE2 & $\begin{array}{l}10 \mathrm{mmol} / \mathrm{l} \mathrm{HCl} \text { adjusted with } \beta \text {-alanine to } \mathrm{pH} 3.5 \\
\mathrm{LE} 2+5 \mathrm{mmol} / \mathrm{L} \beta \mathrm{CD} \\
\mathrm{LE} 2+10 \mathrm{mmol} / \mathrm{L} \beta \mathrm{CD} \\
\mathrm{LE} 2+5 \mathrm{mmol} / \mathrm{L} \mathrm{TM} \beta \mathrm{CD} \\
\mathrm{LE} 2+10 \mathrm{mmol} / \mathrm{L} \mathrm{TM} \beta \mathrm{CD}\end{array}$ \\
\hline LE3 & $10 \mathrm{mmol} / \mathrm{L} \mathrm{HCl}$ adjusted with creatinine to $\mathrm{pH} 4.0$ \\
\hline LE4 & $10 \mathrm{mmol} / \mathrm{L} \mathrm{HCl}$ adjusted with creatinine to $\mathrm{pH} 4.5$ \\
\hline LE5 & $10 \mathrm{mmol} / \mathrm{L} \mathrm{HCl}$ adjusted with creatinine to $\mathrm{pH} 5.0$ \\
\hline LE6 & $10 \mathrm{mmol} / \mathrm{L} \mathrm{HCl}$ adjusted with histidine to $\mathrm{pH} 5.5$ \\
\hline $\begin{array}{l}\text { Terminating } \\
\text { electrolyte } \\
\text { Capillaries }\end{array}$ & $10 \mathrm{mmol} / \mathrm{L}$ caproic acid, $\mathrm{pH} 3.4$ \\
\hline \multicolumn{2}{|c|}{ I (preseparation) $90 \mathrm{~mm} \times 0.8 \mathrm{~mm}$ I.D. } \\
\hline $\begin{array}{l}\text { II (analytical) } \\
\text { Current }\end{array}$ & $90 \mathrm{~mm} \times 0.3 \mathrm{~mm}$ I.D. \\
\hline I & $200 \mu \mathrm{A}$ \\
\hline II & $40 \mu \mathrm{A}$ \\
\hline Detection & Conductivity \\
\hline Injection & $10-\mu \mathrm{L}$ microsyringe \\
\hline Temperature & $22 \pm 2{ }^{\circ} \mathrm{C}$ \\
\hline
\end{tabular}

(1) $0.1 \%$ methylhydroxyethylcellulose was added to all leading electrolytes in order to suppress the electroosmotic flow.

practically significant solute resolution. Owing to the fact that caproic acid interacted very strongly with $\beta C D$ and $\mathrm{TM} \beta \mathrm{CD}$, respectively, the difference limit varied from system to system. Differences lower than $1 \%$ were considered to be negligible.

For a clearer understanding of the experimental data and easier description of the role of cyclodextrins in structural differentiation, the compounds were divided into two groups. The solutes with a common aliphatic chain were included in group $\mathrm{A}$ and the solutes with aromatic and aliphatic ring form group B.

\section{One-dimensional isotachophoresis}

As not all $\mathrm{pK}$ values and mobilities of the hydroxycarboxylic acids are known we have to use the experimental method in order to find a suitable electrolyte system. We have chosen some leading electrolyte systems with $\mathrm{pH}$ values of 3.0, 3.5, 4.0, 4.5, 5.0 and 5.5 (these values were chosen because several hydroxycarboxylic acids have $\mathrm{pK}_{\mathrm{a}}$ 

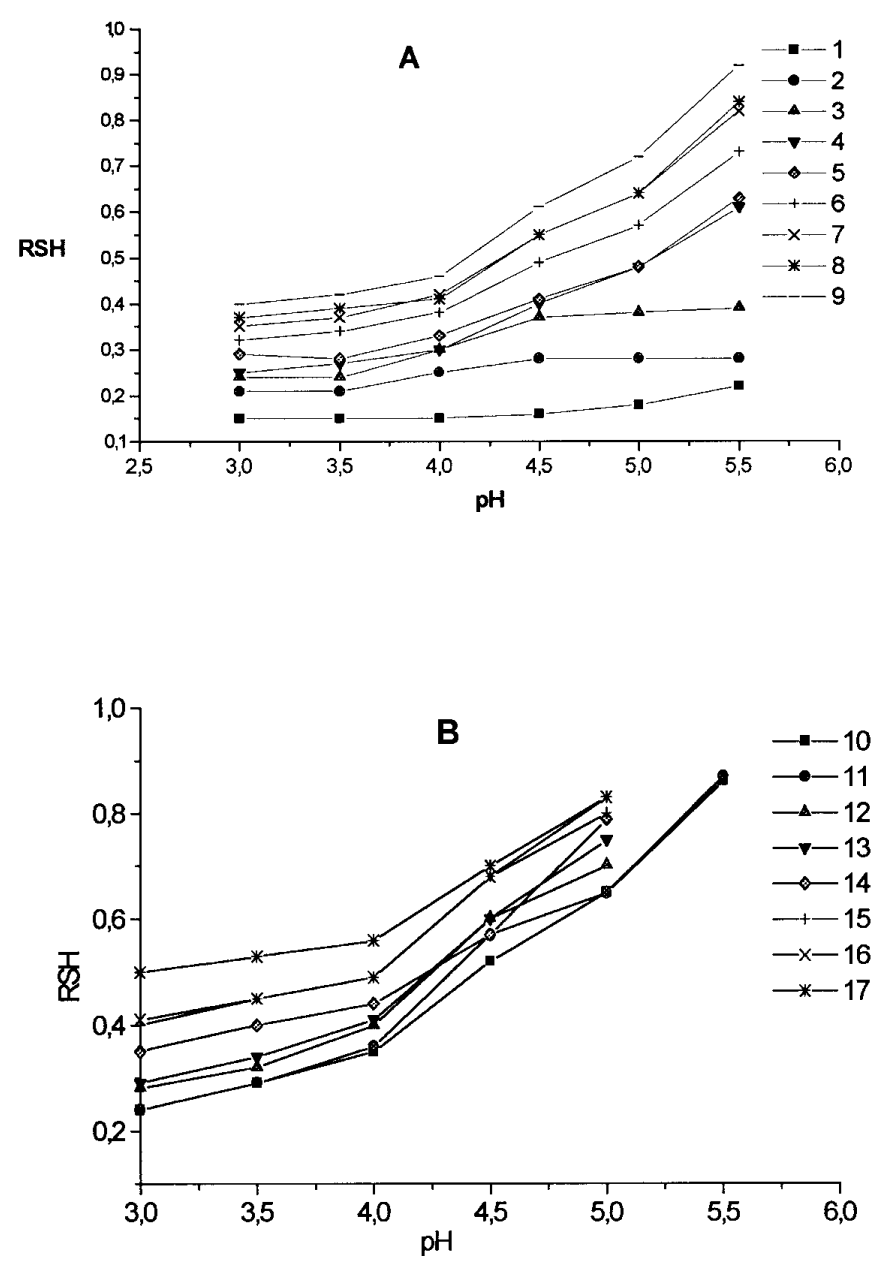

Fig. 1. The relative step height (RSH) values of hydroxycarboxylic acids as a function of $\mathrm{pH}$ of the leading electrolyte, $\mathrm{RSH}=\left(h_{\mathrm{x}}-\right.$ $\left.h_{1}\right) /\left(h_{\mathrm{t}}-h_{1}\right)$. Group A: 1- tartaric acid, 2- malic acid, 3- glyceric acid, 4- 2-methylmalic acid, 5- lactic acid, 6- 2-hydroxybutyric acid, 7- 2-hydroxy-3-methylbutyric acid, 8- 2- hydroxy-2-methylbutyric acid, 9- 2-hydroxy-4-methylvaleric acid. Group B: 10- mandelic acid, 11- atrolactic acid, 12- p-hydroxymandelic acid, 13- 3phenyllactic acid, 14- 3-(4-hydroxyphenyl)lactic acid, 152-hydroxy-4-phenylbutyric acid, 16- hexahydromandelic acid, 17tropic acid. Foe electrolyte systems and conditions, see table II.

values between 3.0 and 5.0 [28]). The conditions for the electrolyte systems are given in table II and the measured relative step heights are shown graphically in figures $1 \mathrm{~A}$ and 1B. It can be seen from Fig. 1A that tartaric, malic, 2hydroxybutyric and 2-hydroxy-4-methylvaleric acid are separated from the other acids over the full $\mathrm{pH}$ range. From the Fig. 1B it is apparent that 3-(4-hydroxyphenyl)lactic and tropic acid are separated from the other anions in the $\mathrm{pH}$ range of the leading electrolyte between 3.0 and 4.0. It can also be seen from Fig. 1A and 1B that maximal differences in relative step heights are obtained at lower $\mathrm{pH}$ values. Therefore, for the separation of the mixture of hydroxycar- boxylic acids we used the leading electrolyte at $\mathrm{pH} 3.0$ and 3.5 , resp. The isotachopherograms of these separations are shown in figures $2 \mathrm{a}$ and $2 \mathrm{~d}$ (group A) and figures $3 \mathrm{a}$ and $3 \mathrm{~d}$ (group B). From the conductivity detector record (Fig. 2a and Fig. 3a), it is appeared that at $\mathrm{pH} 3.0$ of the leading electrolyte, nearly all hydroxycarboxylic acids are likely to be separated; glyceric + 2-methylmalic acid (group A) and p-hydroxymandelic +3 -phenyllactic acid and mandelic + atrolactic acid (group B), however, will comigrate in the mixed zones. At pH 3.5, four mixed zones were obtained (Figs. $2 \mathrm{~d}$ and $3 \mathrm{~d}$ ). In the $\mathrm{pH}$ range between 3.0 and 5.5 the migration order changes for several solutes and the probability of the occurrence of mixed zones is rather high.

The most important information obtained by these measurements is that the complete resolution cannot be achieved by varying the $\mathrm{pH}$ of the leading electrolyte, therefore the structural differences of these solutes were taken as a tool for the adjustment of the separation selectivity.

\section{Two-dimensional isotachophoresis}

Cyclodextrins are known to be useful in the area of structurally related organic compounds and also inorganic ions. In this work, different amounts of $\beta C D$ and TM $\beta C D$ (5 and $10 \mathrm{mmol} / \mathrm{L}$ ) were added to the leading electrolyte to propose isotachophoretic conditions suitable for effective resolution of hydroxycarboxylic acids. The resulting measurements were carried out two-dimensionally. Preseparation capillary was filled with the unmodified leading electrolyte $\mathrm{pH} 3.5$. The $\mathrm{pH}$ of the CD-modified leading electrolyte of the analytical capillary was either 3.0 or 3.5 .

\section{ITP resolution of group $A$ solutes}

\section{Effect of $\beta C D$}

The step height difference of glyceric acid and 2-methylmalic acid with the unmodified electrolyte system $\mathrm{pH} 3.0$ is not significant and the system does not resolved them. Figure $4 \mathrm{a}$ shows the effect of the concentration of $\beta C D$ added to the leading electrolyte at $\mathrm{pH} 3.0$ on the step height of the analyte compounds. By increasing the amount of $\beta C D$ in the leading electrolyte the step height of all the analytes increased (decreased effective mobilities). This effect was most evident for 2-hydroxy-3-methylbutyric, 2-hydroxy-2methylbutyric and 2-hydroxy-4-methylvaleric acid. The addition of $\beta \mathrm{CD}$ to the leading electrolyte at $\mathrm{pH} 3.0$ significantly improves the resolution of glyceric acid and makes it possible to differentiate glyceric acid and 2-methylmalic acid from lactic acid. The best resolution of glyceric, 2methylmalic and lactic acid was achieved at a $\beta C D$ concentration of $5 \mathrm{mmol} / \mathrm{L}$ (Fig. 2b).With this system the stability of the separated zones was verified by construction of calibration lines (see tab. III). The zone lengths were evaluated from the differential conductivity signal of conductivity detector in the analytical capillary. From the correlation coefficients of the calibration equation it can be concluded that the isotachophoretic zones are stable. Higher concentrations lead to a loss in resolution of 2-methylmalic acid 


\section{Original articles}
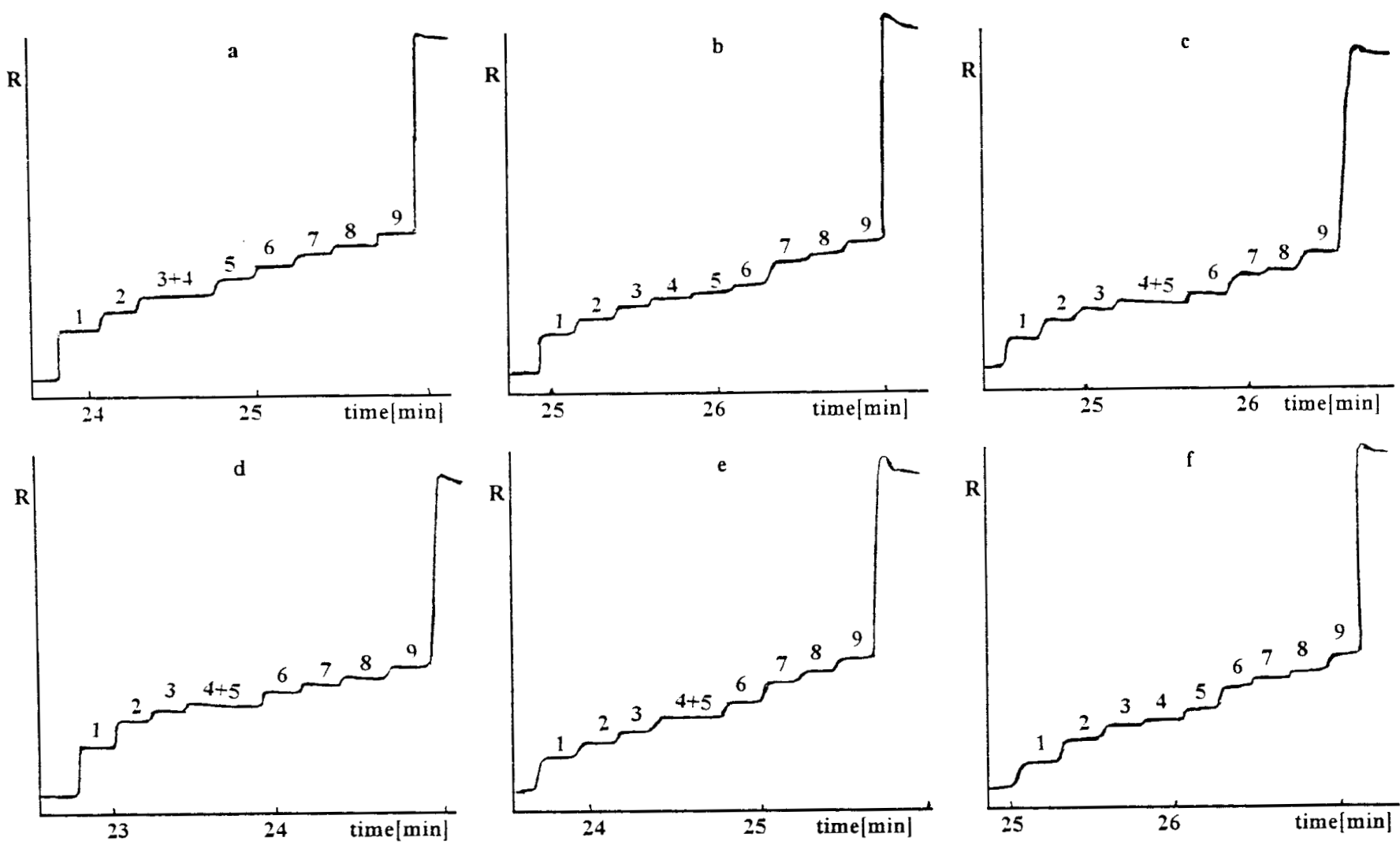

Fig. 2. Isotachophoretic separation of a group A model mixture ( $2 \mathrm{mmol} / \mathrm{L}$ each) by coupling the preseparation capillary filled with system LE2, pH 3.5 and the analytical capillary filled with system LE1, pH 3.0 (a,b,c) or with LE2, pH 3.5 (d,e,f). Electrolyte in the analytical capillary contains $(\mathrm{a}, \mathrm{d}) 0 \mathrm{mmol} / \mathrm{L}$, (b,e) $5 \mathrm{mmol} / \mathrm{L}$ and $(\mathrm{c}, \mathrm{f}) 10 \mathrm{mmol} / \mathrm{L} \beta \mathrm{CD}$. The record $(\mathrm{R})$ from the contact conductivity detector of the analytical capillary is shown. 1- tartaric acid, 2- malic acid, 3- glyceric acid, 4- 2-methylmalic acid, 5- lactic acid, 62-hydroxybutyric acid, 7- 2-hydroxy-3-methylbutyric acid, 8- 2- hydroxy-2-methylbutyric acid, 9- 2-hydroxy-4-methylvaleric acid.

Table III. Linearity of the method in the concentration range 0.08 $-4.0 \mathrm{mmol} / \mathrm{L}$. The equation for the straight line is $y=a+b . x$, where $y$ is the zone length (mm), $a$ is the intercept, $b$ is the slope (absolute injected amount, nmol); $r$ is the correlation coefficient.

\begin{tabular}{lrcc}
\hline Compound & \multicolumn{1}{c}{$a$} & $b$ & $r$ \\
\hline tartaric acid & 0.03 & 17.44 & 0.9997 \\
malic acid & -0.02 & 14.26 & 0.9995 \\
glyceric acid & 0.01 & 16.11 & 0.9998 \\
2-methylmalic acid & 0.15 & 13.28 & 0.9993 \\
lactic acid & 0.11 & 15.04 & 0.9994 \\
2-hydroxybutyric acid & 0.04 & 13.11 & 0.9992 \\
2-hydroxy-3-methylbutyric acid & -0.01 & 10.28 & 0.9996 \\
2-hydroxy-2-methylbutyric acid & -0.09 & 11.78 & 0.9996 \\
2-hydroxy-4-methylvaleric acid & -0.16 & 12.54 & 0.9993 \\
\hline
\end{tabular}

and lactic acid (Fig. 2c). By performing similar isotachophoretic experiments with the leading electrolyte at $\mathrm{pH}$
3.5 an increase in the step heights with increasing amount of $\beta C D$ was observed in all instances (Fig. 4b) except tartaric and glyceric acid; however, this increase was less significant than that obtained at $\mathrm{pH} 3.0$ may be due to the higher dissociation of the acids at $\mathrm{pH}$ 3.5. The resolution increased with increasing amount of $\beta C D$; complete separation was obtained at a $\beta C D$ concentration of $10 \mathrm{mmol} / \mathrm{L}$ (Figs. 2e and 2f).

\section{Effect of $T M \beta C D$}

The effect of TM $\beta C D$ on the step height of group A solutes is shown in figures $4 \mathrm{c}$ and $4 \mathrm{~d}$. Compared with the $\beta C D$, the $\mathrm{TM} \beta C D$ provides a weak retardation effect of hydroxycarboxylic acids. In Fig. $4 d$ it is appeared that most acids cannot be separated with the leading electrolyte $\mathrm{pH}$ of 3.5 modified with TM $\beta C D$; only tartaric, 2-hydroxybutyric and 2-hydroxy-4-methylvaleric acid were separated at this $\mathrm{pH}$. A better separation can be achieved by decreasing the $\mathrm{pH}$ of the leading electrolyte. However, the selectivity in the leading electrolyte $\mathrm{pH} 3.0$ with 5 (10) $\mathrm{mmol} / \mathrm{L}$ TM $\beta C D$ 


\section{Original articles}
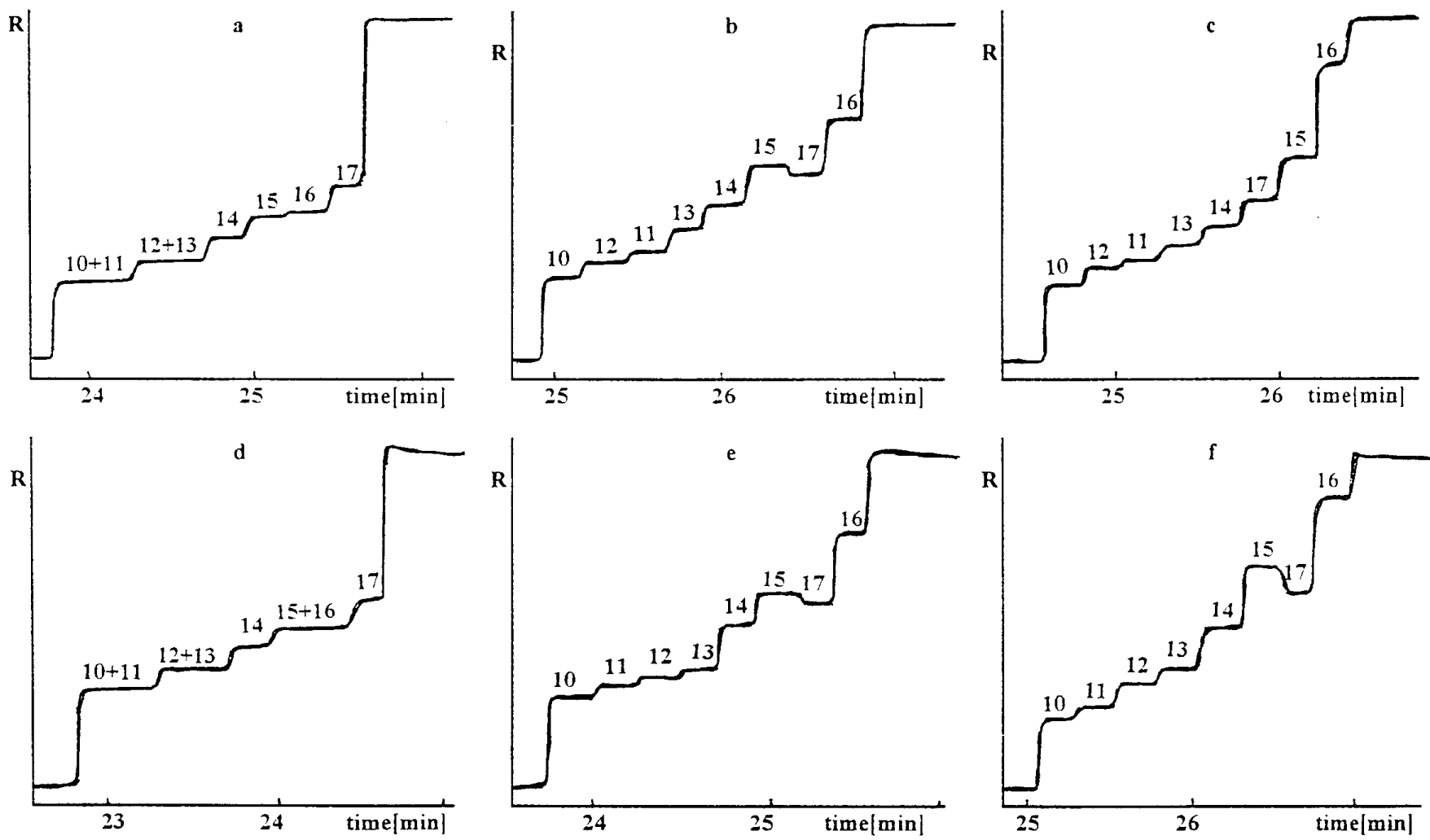

Fig. 3. Isotachophoretic separation of a group B model mixture $(2 \mathrm{mmol} / \mathrm{L}$ each $)$ by coupling the preseparation capillary filled with system LE2, pH 3.5 and the analytical capillary filled with system LE1, pH 3.0 (a,b,c) or with LE2, pH 3.5 (d,e,f). Electrolyte in the analytical capillary contains (a,d) $0 \mathrm{mmol} / \mathrm{L},(\mathrm{b}, \mathrm{e}) 5 \mathrm{mmol} / \mathrm{L}$ and $(\mathrm{c}, \mathrm{f}) 10 \mathrm{mmol} / \mathrm{L} \beta \mathrm{CD}$. The record $(\mathrm{R})$ from the contact conductivity detector of the analytical capillary is shown. 10- mandelic acid, 11- atrolactic acid, 12- p-hydroxymandelic acid, 13- 3-phenyllactic acid, 143-(4-hydroxyphenyl)lactic acid, 15- 2-hydroxy-4-phenylbutyric acid, 16- hexahydromandelic acid, 17- tropic acid.

(see Fig. 4c) is either insignificant (glyceric and 2-methylmalic acid) or completely absent (2-methylmalic and lactic acid). Generally, the addition of TM $\beta C D$ has no positive separation effect.

\section{ITP resolution of group $B$ solutes}

\section{Effect of $\beta C D$}

The effect of $\beta C D$ on the step height of group B solutes is shown in figures $5 \mathrm{a}$ and $5 \mathrm{~b}$. By increasing amount of $\beta C D$ in the leading electrolyte at pH 3.0 all the step heights increased (Fig. 5a) and complete resolution was obtained with $10 \mathrm{mmol} / \mathrm{L} \beta \mathrm{CD}$. With this system the calibration was carried out and from the correlation coefficients of the calibration equation (see tab. IV) it can be stated that the isotachophoretic zones are stable. An increase in the step height with increasing amount of $\beta C D$ was also observed at $\mathrm{pH} 3.5$ but this increase was less significant than that obtained at $\mathrm{pH}$ 3.0. Separation of the mixture of group B solutes with 5 and $10 \mathrm{mmol} / \mathrm{L} \beta \mathrm{CD}$ at $\mathrm{pH} 3.0$ and 3.5 is shown in figure 3. Fairly large changes in the effective mobilities and migration orders are obtained, but the leading electrolyte at
$\mathrm{pH} 3.5$ with $5 \mathrm{mmol} / \mathrm{L} \beta \mathrm{CD}$ gives identical separation as a $10 \mathrm{mmol} / \mathrm{L} \beta \mathrm{CD}$ (Figs. 3e and 3f). Large decreases in effective mobilities are observed for hexahydromandelic and 2hydroxy-4-phenylbutyric acid. The most interesting feature of the leading electrolyte at $\mathrm{pH} 3.5$ modified with $\beta \mathrm{CD}$ is the enforced migration [30] of 2-hydroxy-4-phenylbutyric acid ahead of tropic acid.

\section{Effect of $T M \beta C D$}

Figures $5 \mathrm{c}$ and $5 \mathrm{~d}$ shows the relationship between the amount $\mathrm{TM} \beta \mathrm{CD}$ added to the leading electrolyte at $\mathrm{pH} 3.0$ (3.5) and the step height of the group B solutes. By adding $\mathrm{TM} \beta C D$ to the leading electrolyte, a weak reduction in effective mobility was observed for all compounds, but an increase in the amount of TM $\beta C D$ did not result in complete resolution. Generally, the effective mobilities of the eight examined compounds were reduced more effectively by using $\beta C D$ than TM $\beta C D$.

The main parameters affecting separations with CD-based electrolytes are the nature and concentration of the $\mathrm{CD}$ and leading electrolyte $\mathrm{pH}$. Concerning the nature of the $\mathrm{CD}$, 


\section{Original articles}
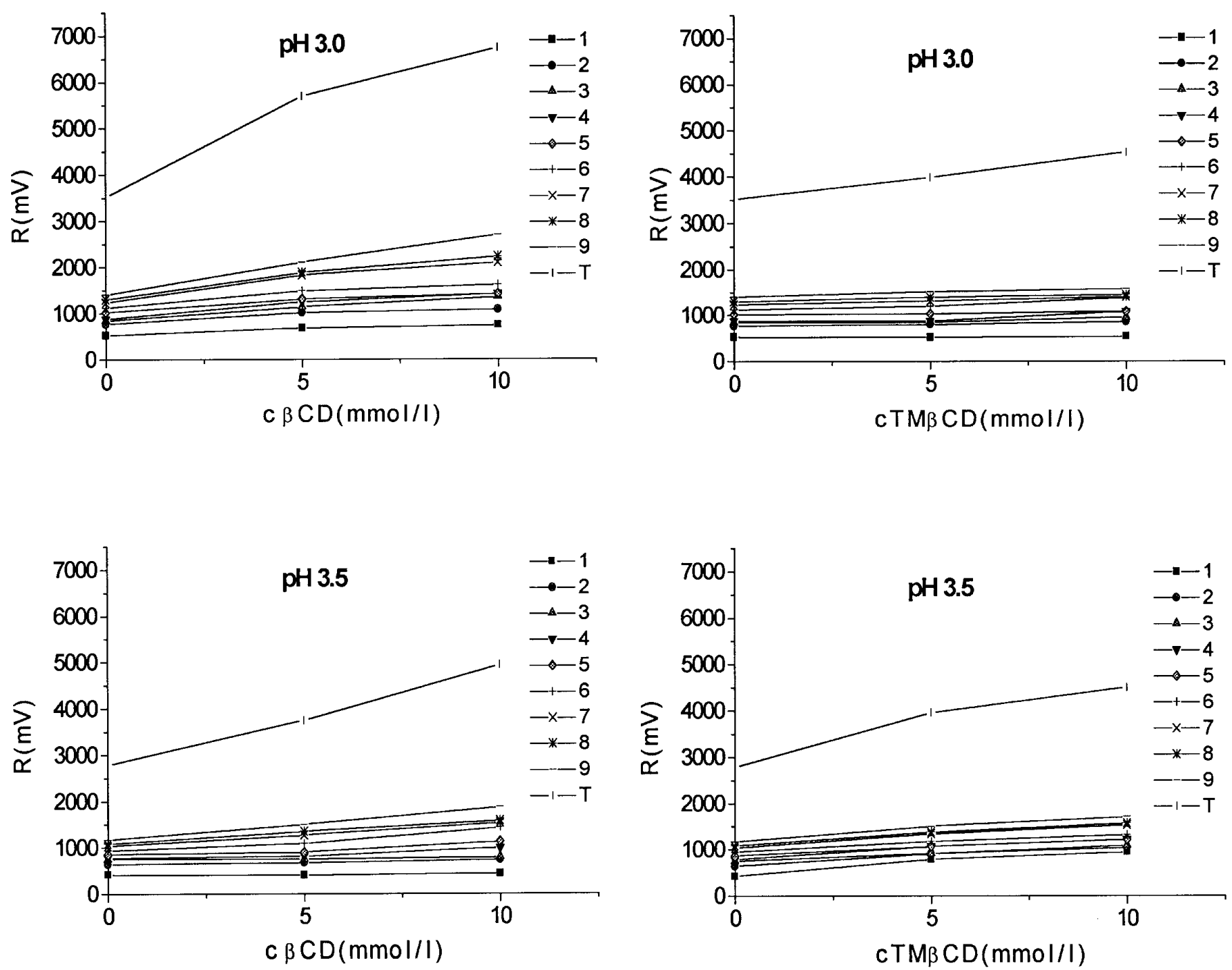

Fig. 4. Effect of $\beta C D(a, b)$ and $\operatorname{TM} \beta C D(c, d)$ concentration on the step height of the group A solutes. Experimental conditions and symbols as in Fig. 2 ( $\mathrm{T}$ - terminating ion).

Table IV. Linearity of the method in the concentration range 0.08 $-4.0 \mathrm{mmol} / \mathrm{L}$. The equation for the straight line is $y=a+b . x$, where $y$ is the zone length (mm),,$a$ is the intercept, $b$ is the slope (absolute injected amount, nmol); $r$ is the correlation coefficient.

\begin{tabular}{lrcc}
\hline Compound & \multicolumn{1}{c}{$a$} & $b$ & $r$ \\
\hline mandelic acid & -0.03 & 15.23 & 0.9994 \\
atrolactic acid & 0.05 & 14.32 & 0.9995 \\
p-hydroxymandelic & 0.11 & 12.21 & 0.9993 \\
3-phenyllactic acid & 0.11 & 10,19 & 0,9996 \\
3-(4-hydroxyphenyl)lactic acid & 0.12 & 11.59 & 0.9996 \\
2-hydroxy-4-phenylbutyric acid & 0.08 & 11.22 & 0.9995 \\
hexahydromandelic acid & 0.02 & 10.99 & 0.9994 \\
tropic acid & 0.01 & 10.72 & 0.9995 \\
\hline
\end{tabular}

$\beta C D$ leads to more stable inclusion complexes than TM $\beta C D$. TM $\beta C D$ is characterised by the presence only of methyl groups and the absence of primary and secondary hydroxyl group on rim. The methylation of all hydroxyl groups makes the $\beta C D$ more flexible and should lead to a better fit with analytes. However, $\beta C D$ appeared to be better complexing agent than TM $\beta C D$. This indicates that hydroxyl groups of $\beta C D$ are involved in the complexation of hydroxycarboxylic acids and the hydrogen bonding occurs. When the length of the alkyl chain of group A acids was increased, the retardation increased with the $\beta C D$, whereas it remained almost constant with the TM $\beta C D$. This trend also supports hydrophilic interactions. The higher complexation for group $\mathrm{B}$ solutes in case $\beta \mathrm{CD}$ could be attributed to the aromatic ring in the structure of group B, which is more likely fit in the hydrophobic cavity of the $\mathrm{CD}$ than the aliphatic chain of 


\section{Original articles}
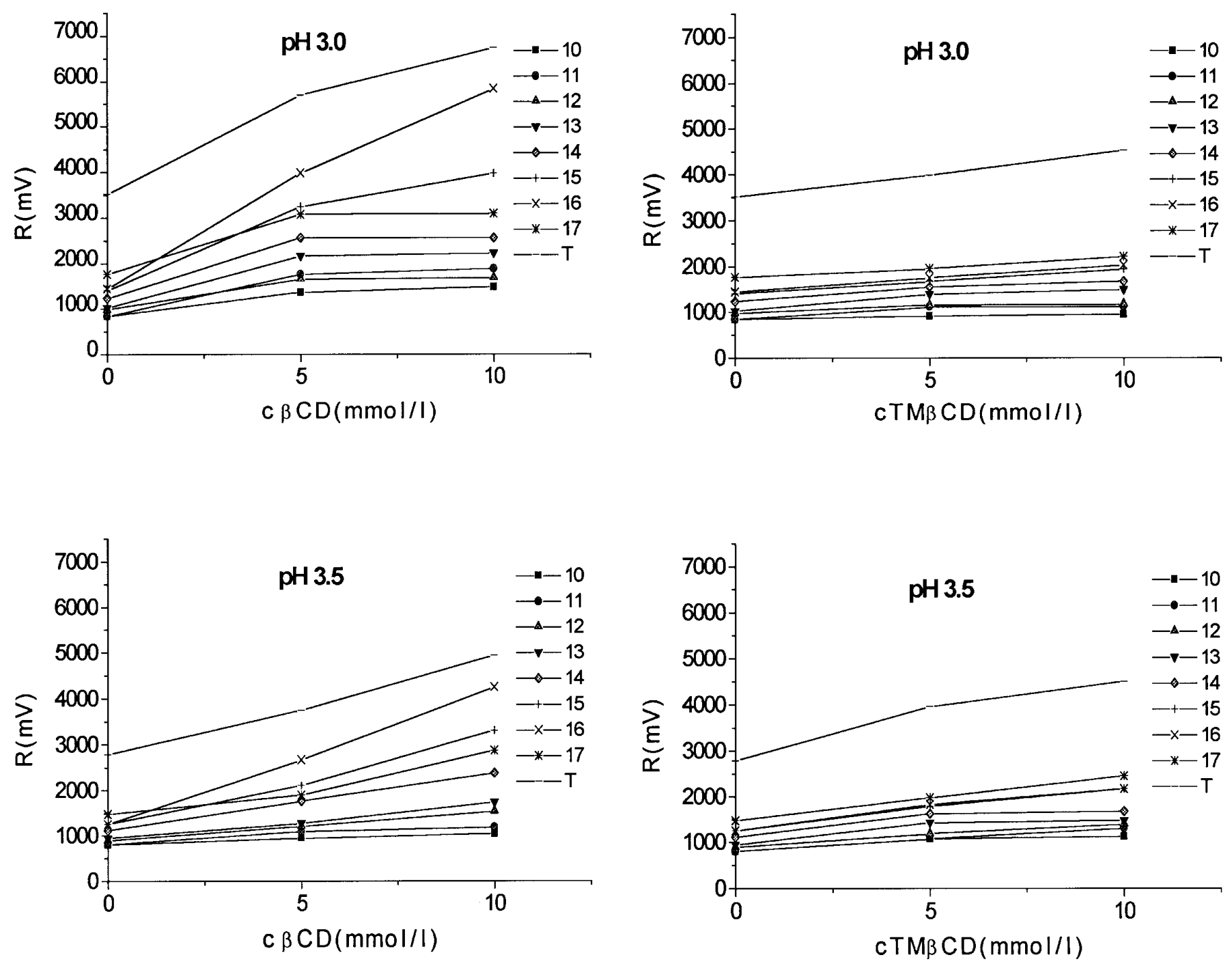

Fig. 5. Effect of $\beta C D(a, b)$ and $\operatorname{TM} \beta C D(c, d)$ concentration on the step height of the group B solutes. Experimental conditions and symbols as in Fig. 3 ( $\mathrm{T}$ - terminating ion).

group A solutes. With both the CDs studied, the hydroxycarboxylic acids formed more stable inclusion complexes at $\mathrm{pH} 3.0$ than at other $\mathrm{pH}$ values probably due to the higher inclusion of the solutes when they are in their less dissociated form. These results indicated that hydrophobic interactions and hydrogen bonding occur in combination in the separation mechanisms.

\section{Conclusions}

The comparative measurements with $\beta C D$ and its trimethyl derivative showed that the selectivity is highly influenced by the size and the hydrophobicity of the cavity. It can be concluded that the $\beta C D$ is able to form relatively stable complexes with the compounds studied, but the effective resolution depends on the choice of the suitable $\mathrm{pH}$ of leading electrolyte.

\section{Acknowledgements}

Financial support of this work by VEGA (Slovak Republic) grant G 703 is acknowledged.

\section{References}

1. Snopek, J.; Jelínek, I.; Smolková-Keulemansová, E. J. Chromatogr. 1988, 452, 571-590.

2. Jelínek, I.; Dohnal, J.; Snopek, J.; Smolková-Keulemansová, E. J. Chromatogr. 1989, 464, 39-147. 


\section{Original articles}

3. Jelínek, I.; Snopek, J.; Dian, J.; Smolková-Keulemansová, E. J. Chromatogr. 1989, 470, 113-121.

4. Tanaka, S.; Kaneta, T.; Taga, M.; Yoshida, H.; Ohtaka, H. J. Chromatogr. 1991, 587, 364-367.

5. Dubrovcáková, E.; Gas, I B.; Vacík, J.; SmolkováKeulemansová, E. J. Chromatogr. A 1992, 623, 337-344.

6. Blatny,uP.; Kvasnickla, F.; Kenndler, E. J. Chromatogr. A 1996, 737, 255-262.

7. Miwa, H.; Yamamoto, M.; Kan, K.; Futata, T.; Asano, T. $J$. Chromatogr. B 1996, 679, 1-6.

8. Miwa, M.; Yamamoto, M. J. Chromatogr. A 1996, 721, 261268.

9. Rathore, H. S. J. Chromatogr. A 1995, 733, 5-17.

10. Révész, G.; Hajós, P.; Csiszár, H. J. Chromatogr. A 1996, 753, 253-260.

11. Ding, M.-Y.; Chen, P.-R.; Luo, G.-A. J. Chromatogr. A 1997, 764, 341-345.

12. Yu, H. J. Chromatogr. A 1997, 769, 333-337.

13. Suzuki, Y. J. Chromatogr. A 1997, 773, 123-130.

14. Souza, S. R.; Tavares, M. F. M.; de Carvalho, L. R. F. J. Chromatogr. A 1998, 796, 335-346.

15. Chen, H.; Xu, Y.; Van Lente, F.; Ip, M. P. C. J. Chromatogr. B 1996, 679, 49-59.

16. Arellano, M.; Andrianary, J.; Dedieu, F.; Couderc, F.; Puig, Ph. J. Chromatogr. A 1997, 765, 321-328.
17. Zeman, A. J. J. Chromatogr. A 1997, 787, 243-251.

18. Chang, H.-T.; Chen, H.-S.; Lee, R. J. Chromatogr. A 1998 , 800, 339-344.

19. Tschope , W.; Ritz, E. J. Chromatogr. 1980, 221, 59.

20. Dolník, V.; Bocek P. J. Chromatogr. 1981, 225, 455.

21. Karovicolvá, J.; Polonsky,uJ., Príbela A. Nahrung 1990, 34, 665.

22. Karovicolvá, J.; Príbela, A.; Polonsky,uJ. J. Chromatogr. 1990, 509, 283.

23. Krivánková, L.; Bocek, P. J. Microcol. Sep. 1990, 2, 80.

24. Oefner, P.; Hafele, R.; Bartsch, G.; Bonn, G. J. Chromatogr. 1990, 516, 251.

25. Reijenga, J. C.; Trieling, R. G.; Kaniansky, D. J. Chromatogr. 1993, 638, 195

26. Blatny,uP.; Kvasnicka, F.; Kenndler, E. J. Chromatogr. A 1996, 737, 255.

27. Nowotny, H. P.; Schmalling, D.; Wistuba, D.; Schurig, V. J. High Resolut. Chromatogr. 1989, 12, 383.

28. Hirokawa, T.; Nishing, M.; Aoki, N.; Kiso, Y.; Sawamoto, Y.; Yagi, T.; Akiyama, J.-I. J. Chromatogr. 1983, 271, D1-D106.

29. Dictionary of Organic Compounds Champan and Hall: New York, 1982, Volume 3.

30. Gebauer, P.; Bocek, P. J. Chromatogr. 1983, 267, 49. 